\begin{tabular}{c} 
Volume and Issues Obtainable at Center for Sustainability Research and Consultancy \\
Journal of Business and Social Review in Emerging Economies \\
ISSN: 2519-089X (E): 2519-0326 \\
Volume 5: No. 1, June 2019 \\
JSRᄃ \\
Journal homepage: www.publishing.globalcsrc.org/jbsee \\
\hline
\end{tabular}

\title{
Emergent Typologies of Small Businesses in a Multi-ethnic Wet Market in Malaysia: A Phenomenological Study
}

\author{
${ }^{1}$ Teik AunWong \\ ${ }^{1}$ Inti International College Penang Email: teikaun@yahoo.com
}

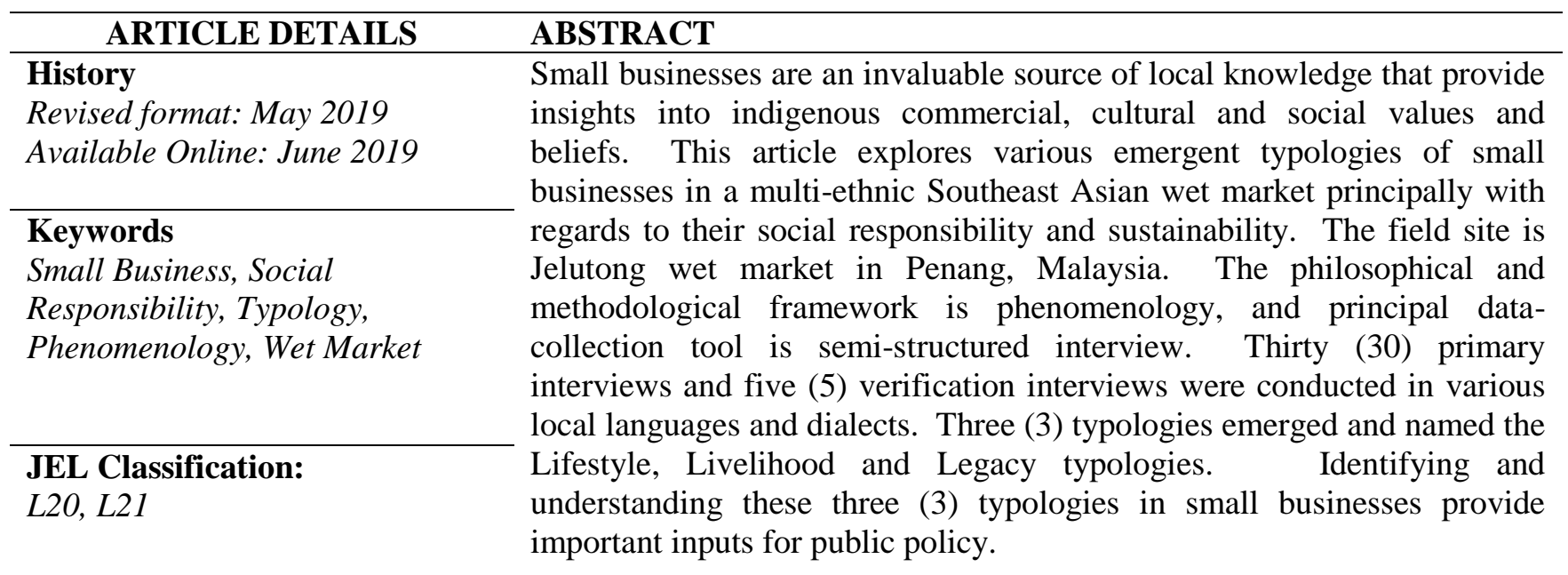

(C) 2019 The authors, under a Creative Commons AttributionNonCommercial 4.0

Corresponding author's email address: teikaun@yahoo.com

Recommended citation: Wong, T. A. (2019). Emergent Typologies of Small Businesses in a Multi-ethnic Wet Market in Malaysia: A Phenomenological Study. Journal of Business and Social Review in Emerging Economies, 5 (1), 191-200

DOI: $10.26710 /$ jbsee.v5i1.620

\section{Introduction}

Small businesses form the backbone of most nations' economies. Small businesses include incorporated small and medium enterprises (SME's), un-incorporated businesses, individuals operating with business licenses, unregistered businesses and individuals operating without business licenses. In Malaysia, 97\% of business establishments are SME's and they account for $65 \%$ of the country's employment. SME's are responsible for nearly $36 \%$ of the country's GDP and nearly 18\% of Malaysia's exports (The World Bank, 2017). In Pakistan, SME's are considered as "engines of economic growth and have major input towards sustainable gross domestic product (GDP)" (Rasheed \& Rahman, 2016). Approximately 3 million SME's in Pakistan account for $90 \%$ of overall businesses, employ $70 \%$ of the labor force, contribute $30 \%$ towards the GDP and $25 \%$ towards the country's total earnings (Robu, 2013; Khan \& Khalique, 2014). As such, SMEs play a crucial role in both the Malaysian and Pakistani economies in terms of output, employment, exports and innovation1. Similarly in the UK, "There is no location

$1 \mathrm{SME}$ 's are also predominantly indigenous to the local economy and are thus more entrenched and unlikely to shift their operations outside the country. This is in contrast to large corporation many of whom operate across different countries and are less entrenched or embedded into a particular country. These multi-national corporations usually have no qualms about shifting their operations around different countries to suit their business needs. In the process, considerable dislocation and disruption of the local economy and community could occur. 
which is not dominated by small firms in numerical terms, since small and medium-sized firms account for over 99 percent of businesses in all regions (although regional sectoral density does vary across regions). This is why, at least collectively, small firms and their practices play a significant role in the UK today, and should, therefore, not be excluded from debates on business ethics and social responsibility." (Spence \& Rutherford, 2000)

Despite the evident importance of small businesses, they are not frequently the focus of research in terms of social responsibility and sustainability. "Extant research on CSER (Corporate Social and Environmental Reporting) uses a very limited range of theoretical lenses. The vast majority of research uses legitimacy theory, stakeholder's theory and institutional theory as the main conceptual basis. This limited choice of theory has implications for the limited insights on CSER (Mahmood \& Ahmad, 2015). Furthermore, research on the social impact of businesses traditionally focusses on large firms and attention on small businesses is only recently gaining traction (Quinn, 1997; Spence, 1999; Vyakarnam et al, 1997). This is partly attributed to the fact that small businesses are difficult to identify, track and comprehensively studied. Small businesses typically operate using local languages and this presents a barrier to researchers not versed in those languages. In societies that are multi-ethnic as in the case of Malaysia and many Southeast Asian countries, the myriad of languages and dialects used even within a localized community compounds the difficulty. On top of linguistics, the cultural, social and religious context have to be considered and accounted. Even gender variations have to be considered in the milieu (Ahmad \& Seet, 2010). Nonetheless, the value of scholarship on small businesses in Southeast Asia is significant as they possess a distinct local characteristic and are largely free from foreign influence. As such, they provide an insight into indigenous commercial, cultural and social practices as well as beliefs.

\section{Research Field Site}

The field site selected for this study is Jelutong wet market in the state of Penang in Malaysia. In Malaysia and most parts of Asia, wet markets are relatively common and ubiquitous microcosms of indigenous commerce and communities2. The vendors in wet markets consist of individual small businesses. An operating license is required and a monthly fee paid to the local municipal or city council. Priority for operating license is usually given to local small businesses3. Wet markets are the archetypical 'free marketplace' espoused in economics by Adam Smith. Adam Smith described the free marketplace where prices are determined by supply and demand "where there is perfect liberty, or where he may change his trade as often as he pleases" (Smith, 2007). Adam Smith elaborated by contrasting the free marketplace with a monopoly. "The price of monopoly is upon every occasion the highest which can be got. The natural price, or the price of free competition, on the contrary is the lowest which can be taken, not upon every occasion, indeed, but for any considerable amount of time". The characteristics of wet markets in Southeast Asia closely approximate Smith's 'free marketplace' and serve as a suitable proxy for the free market economy in general. A wet market also serves as a representative of society in general. "The social interaction of the people is also important in the society and they connect each other in different sectors of society" (Ali, Chaudhary \& Farooq, 2018).

\section{Methodology}

The principal data collection instrument employed is semi-structured interviews. The structured component gather basic data of the respondents. The non-structured component comprises free and flexible discussions with respondents on topics of their interest. This allows for new areas deemed important by respondents to emerge and inform the subsequent analysis.

The language used is the language the respondents are most comfortable in expressing themselves. As a result, a multitude of languages and dialects are used such as Hokkien (the local Penang Chinese dialect), colloquial Malay (otherwise known as "Bahasa Pasar" or literarily "market language"), English and Mandarin. This linguistic diversity reflects the multi-ethnic context of Jelutong wet market in particular and Malaysian society in general.

2 It is noted that in bigger towns and cities in Malaysia such as Kuala Lumpur, Johor Bahru and George Town, wet markets are slowly and surely giving way to encroaching modern hypermarkets and shopping malls. This parallels the situation in America where the expansion of modern mass retailers particularly Walmart has seen the demise of many traditional "mom and pop" stores and small businesses.

3 In Penang there it is an explicitly stated policy that only Malaysian citizens can be granted an operating license as wet markets are considered a form of social service that costs considerable tax monies. The license fees are usually a token sum far insufficient to cover the cost of building and maintaining a wet market. 
The semi-structured interviews employ the framework of phenomenology. Phenomenology is a broad concept and has been "conceptualized as a philosophy, a research method and an overarching perspective from which all qualitative research is sourced" (Maykut \& Morehouse, 1994). Phenomenology focuses on describing and interpreting a particular phenomenon from the social actors' perspective, experience and understanding. "Phenomenology is an approach that focuses on how life is experienced. It is not primarily concerned with explaining the causes of things but tries, instead, to provide a description of how things are experienced first-hand by those involved" (Denscombe, 2007).

The analysis of data obtained from semi-structured interviews adopts Schutz's methodological approach (Schutz, 1963). The strength of this approach lies in its ability to give voice to social actor's authentic accounts of complex phenomena and systematically interpret and analyze the phenomenon to articulate a conceptual framework. In line with the philosophy of phenomenology an abductive research strategy is employed. Abductive research strategy starts with adducing everyday lay concepts, meanings and motives of social actors and finishes with developing a theory that is iteratively tested (Blaikie, 2007). To operationalize abductive research strategy, the social actors' accounts of their actions in everyday language are obtained and referred to as first-level constructs or everyday typifications. Subsequently, social scientific concepts referred to as second-level constructs or typologies are generated to describe the first-level constructs. The typologies are then tested by translating back to everyday language and referring back to the social actors. If the social actors do not accept the typologies, revisions are required until they are accepted (Ong, 2010).

\section{Respondent Pool}

Purposeful sampling is used in the respondent selection. "Purposeful sampling is a technique widely used in qualitative research for the identification and selection of information-rich cases for the most effective use of limited resources" (Patton, 2002). "There exists numerous purposeful sampling designs. Examples include the selection of extreme or deviant (outlier) cases for the purpose of learning; the selection of cases with maximum variation for the purpose of documenting unique or diverse variations that have emerged in adapting to different conditions, and to identify important common patterns that cut across variation; and the selection of homogeneous cases for the purpose of reducing variation, simplifying analysis, and facilitating group interview" (Palinkas et al., 2013).

A total of thirty (30) separate semi-structured interviews was conducted and recorded. The length of the interviews ranges from six (6) to thirty nine (39) minutes. A further five (5) informal verification interviews was conducted with the original respondents for verification of the appropriateness of the typologies. All of them agreed that the emergent typologies represent a good spectrum of the attitude and mindset of small businesses in Jelutong wet market.

\section{Results and Analysis}

The responses from respondents are analyzed from two (2) perspectives. Firstly, they are deliberated based on their views on business, legality, morality and philanthropy. Secondly, they are viewed based on a comparison by trade, age, period in business and legality of the business. From these two (2) perspectives, eighteen (18) first-order construct or everyday typifications are captured as emergent themes listed below:

$\# 1$ - Tendency to down-play business operations is present.

\#2 - Business is conducted in a casual manner or as a "Lifestyle".

\#3 - Legality is not an intrinsic concern.

\#4 - Legal businesses do not begrudge the illegal ones.

\#5 - Legal businesses have a positive view of the state of the economy.

\#6 - Reasonable and non-exploitative pricing is an ethical concern.

\#7 - Profitability is a prime concern.

\#8 - Ensuring quality of product is an ethical concern.

\#9 - Providing good service is an ethical concern.

$\# 10$ - Ethical behavior is also expected of the customers

\#11 - Recipients of charity must be deserving.

\#12 - Charity can also assume non-monetary forms.

\#13 - Religion influences philanthropic orientations.

\#14 - The absence of doing evil equates to doing good. 
\#15 - Type of trade has a bearing on attitudes towards charity.

\#16 - Respondents above fifty (50) years lean toward "Business as a Lifestyle".

\#17 - Different periods in business influence respondents' openness.

\#18 - Legality is viewed as a rubbery concept.

Three (3) second-order constructs or emergent typologies were derived from the iterative analysis of the data and emergent themes. The respondents' world-view revolves around their business which is unsurprisingly as they are all small businesses in a busy wet market. Some respondents were interviewed twice but they are counted only once in the typology tabulation. These typologies are to be viewed as a spectrum as befit the inherent subjective nature of social phenomena. These three (3) emergent typologies are named Lifestyle, Livelihood and Legacy typologies4.

\subsection{Lifestyle Typology}

The first emergent typology is the Lifestyle typology. Emergent themes associated with the Lifestyle typology are as follows:

\#2 - Business is conducted in a casual manner or as a "Lifestyle".

\#4 - Legal businesses do not begrudge the illegal ones.

\#6 - Reasonable and non-exploitative pricing is an ethical concern.

$\# 8$ - Ensuring quality of product is an ethical concern.

$\# 12$ - Charity can also assume non-monetary forms.

$\# 13$ - Religion influences philanthropic orientations.

\#16 - Respondents above fifty (50) years lean toward "Business as a Lifestyle".

Respondents are not desperate to earn money and does business primarily as a pass-time or recreation. This mindset is aptly summed by the Hokkien phrase "kui jit" ("pass day"). Having said this, they are not operating a charity or non-profit enterprise. Business still goes on, but social activities are present alongside and in some instances overshadow commercial ones.

It helps that most of the respondents in this typology are financially stable and do not fully depend on their business to materially support themselves or their families. All of them are above fifty (50) years of age and most are operating their business in Jelutong wet market for more than ten (10) or even twenty (20) years. Some of them are second generation businesses. Even those who are operating in Jelutong wet market for less than ten (10) years have work experience elsewhere.

Their ethical system is based on providing and ensuring quality in their products followed by fair and appropriate pricing. There is a discernible sense of pride in the quality of their products and having a good reputation for quality products is of utmost importance. As there is hardly any distinction between the business and the businessowner among small businesses in Jelutong wet market, this favorable reputation goes beyond their products and is reflected onto them as honorable and reputable individuals.

Most respondents do charity with several of them indicating that they contribute a lot in terms of frequency and quantum. The high quantum of charity points to the lower prominence of profit-making. Social capital considerations such as socializing, contributing towards community and simply being happy play a prominent role. Doing charity by being meaningfully involved in charitable organizations and contributing time, money and effort contributes towards these objectives. Economic considerations are not cast away but significant consideration is given to social capital formation.

4 Current research on small businesses have identified several typologies namely the "Lifestyle firm", "Salarysubstitute firm" and "Entrepreneurial firm" (Barringer \& Ireland, 2012). Coincidentally the term "Lifestyle" is also used for one of the typologies identified in this article. Nonetheless, the meaning and context is different as the "Lifestyle firms" referred to in the earlier literature are businesses that provide the owner the opportunity to pursue or explore a particular lifestyle and earn a living while doing so. Examples include ski instructors, golf and tennis professionals, wine bars and tour guides. 


\subsection{Livelihood Typology}

The second emergent typology is the Livelihood typology. Emergent themes associated with the Livelihood typology are as follows:

\#1 - Tendency to down-play business operations is present.

\#3 - Legality is not an intrinsic concern.

\#6 - Reasonable and non-exploitative pricing is an ethical concern.

\#7 - Profitability is a prime concern.

\#9 - Providing good service is an ethical concern.

$\# 10$ - Ethical behavior is also expected of the customers

\#11 - Recipients of charity must be deserving.

$\# 14$ - The absence of doing evil equates to doing good.

$\# 18$ - Legality is viewed as a rubbery concept.

Respondents are actively engaged in business predominantly to make money to materially support themselves and their families if applicable. This attitude towards business is aptly summed by the phrase "tharn chiak" in Hokkien and "cari makan" in colloquial Malay. In other words, their hard work is not a choice but a necessity to make a living and many are also the primary bread-winner of their families. Non-economic concerns such as accumulating social capital are secondary albeit still present.

Their ethical system is primarily based on providing reasonable and competitive pricing. As their main preoccupation is to make a living, the appropriate pricing is a prime concern as it immediately translates into quantum of profits. Having said this, they do not indiscriminately or exploitatively price. They view reasonable and appropriate pricing as the "right thing to do" or as an ethical behavior.

Most do perform charity albeit in small amounts and none indicate that they do charity "a lot". The fact that the majority do charity is noteworthy given that none of them appear to be particularly wealthy and their main objective in Jelutong wet market is to make a living5. In the course of making a living, they do not disassociate themselves from helping others. As exemplified by a respondent who sells rice meals, she empathizes with other whom she described as "orang susah" (people in hardship) as she is also an "orang susah".

Most are aged fifty (50) years or less and operating in Jelutong wet market for less than ten (10) years. Their comparatively shorter business presence in Jelutong wet market makes them less socially connected to the place compared to those that have been operating longer. Furthermore, many also conduct business in places other than Jelutong wet market and thus spread out their social capital among acquaintances in different localities.

\subsection{Legacy Typology}

A third emergent typology is the Legacy typology. Emergent themes associated with the Livelihood typology are as follows:

\#6 - Reasonable and non-exploitative pricing is an ethical concern.

\#7 - Profitability is a prime concern.

\#8 - Ensuring quality of product is an ethical concern.

$\# 11$ - Recipients of charity must be deserving.

$\# 12$ - Charity can also assume non-monetary forms.

\#13 - Religion influences philanthropic orientations.

The distinct feature is that respondents are working hard even though they are not dependent on the money earned from their business. Working hard on their business is not perceived as a means (earning more money) towards an end (a presumably more comfortable life). Rather, it is an end by itself.

Respondents in the Legacy typology are all above fifty (50) years of age and do not need to support their children anymore as they are all grown up and independent. Their ethical system is predominantly based on quality considerations and they take pride in freshness of their products and in honestly communicating with customers. 
All respondents practice charity with one respondent doing it on a high scale in relation to his socio-economic situation.

The distinctively unique characteristics of respondents in Legacy typology is their approach towards business. They are hard at work but are not entirely dependent on the money earned from the business. In other words, their hard work is not a necessity for making a living but is a conscious or perhaps subconscious choice. They are all above fifty (50) years old and do not need to support their children unlike the Livelihood typology whom the majority are below fifty (50) years of age. The fact that they are all already over fifty (50) years old and mostly operating in Jelutong wet market for over twenty (20) years indicate that they are not "transiting" from the Livelihood to the Lifestyle typologies due to advancing age. They are fixed in their outlook towards business. They pursue their business as a predominantly economic concern even though they could conceivably switch to the more socially-oriented Lifestyle typology approach. It is noted that in the Livelihood typology there are also respondents above 50 years of age. However, these respondents are still working primarily to support themselves.

In contrast, all respondents in Legacy typology state that their children are already grown-up, independent and with some of them indicating that they are actually being supported by their children. It is postulated that the respondents in the Legacy typology started in the Livelihood typology when they were younger and had to work hard to support themselves and their families. Subsequently, their socio-economic situation improved and they successfully provided for their family economically and raised their children. At this stage of life when they are over 50 years old respondents in the Legacy typology did not transit to the Lifestyle typology with regards to the mindset and attitude towards business. Consciously or perhaps subconsciously, they continued to adhere to the Livelihood typology mindset and attitude even though they are economically already more secure and do not need to work as hard as when they were in Livelihood typology.

As such, the term "Legacy" to describe this typology is deemed apt to describe the legacy of their earlier mindset and attitude. Working hard to earn money is not perceived as a means to an end to support themselves, their families and their children. Rather, hard work is conceived as an end in itself and vigorously pursued even when the necessity and urgency have diminished. In other words, hard work is perceived as a worthy and meritorious endeavor in and on itself.

\subsection{Summary of Typologies}

The characteristics of the Lifestyle, Livelihood and Legacy typologies are summarized below:

Lifestyle Typology

Social considerations - commercial and social concerns are approximately equal

Business ethics - primarily based on ensuring quality of product

Charity - higher quantum

Trade - equal in raw food and cooked food, least in non-food

Age - all over fifty (50) years of age

Livelihood Typology

Social considerations - commercial concerns as the base followed by social concerns

Business ethics - primarily based on reasonable pricing

Charity - lower quantum

Trade - mostly in non-food, least in raw food

Age - majority less than fifty (50) of age

Legacy Typology

Social considerations - commercial concerns as the base followed by social concerns

Business ethics - primarily based on ensuring quality of product

Charity - higher quantum

Trade - mostly in raw food

Age - all over fifty (50) years of age

Table 1 - Summary of the characteristics of Lifestyle, Livelihood and Legacy typologies

The Legacy typology shares similarities with Livelihood typology in employing economic considerations as the base of their outlook. However, as noted earlier their motivations are different. The Legacy typology also shares similarities with Lifestyle typology in their shared focus on quality as the main ethical concern and higher 
propensity for charity. This suggests that the weightage ratio of economic consideration vis-à-vis ethical and social considerations is closer to that of Lifestyle typology.

It is postulated that the bulk of young businesses start in a Livelihood typology and as they progress in years and economic standing, they might switch to other typologies. The following diagram depicts the postulated temporal relationship among the different typologies:

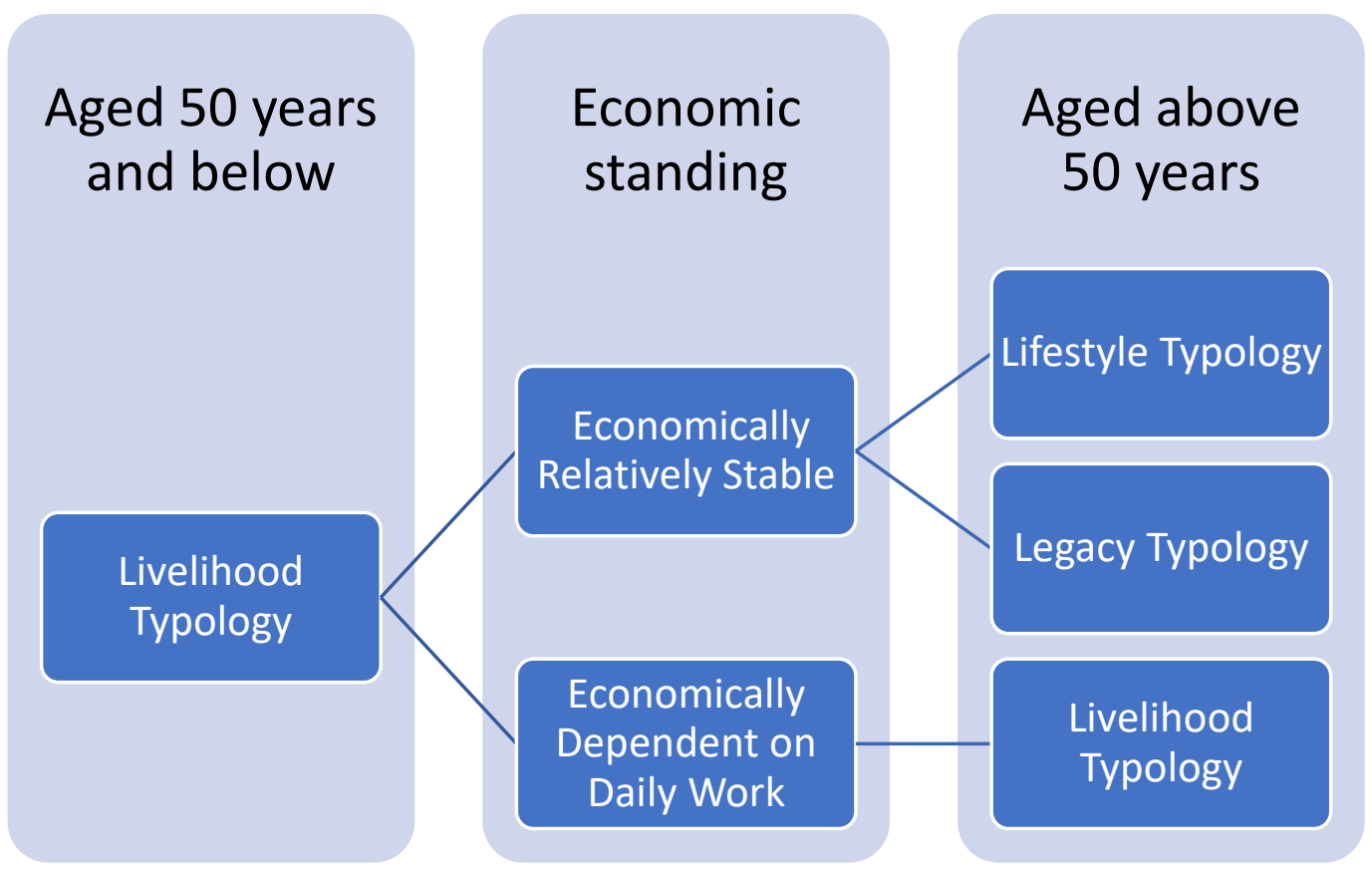

Figure 1 - Postulated temporal relationship among Lifestyle, Livelihood and Legacy typologies

\section{Conclusion and Public Policy Implications}

The emergence of the Lifestyle, Livelihood and Legacy typologies among small businesses in Jelutong wet market is a novel and significant finding. The Lifestyle typology is unique towards small businesses as their commercial and social considerations are roughly balanced and inter-twined to the extent that they are difficult to distinguish or separate. For Lifestyle typology and to a lesser extent Legacy and Livelihood typologies, business is a social activity that goes beyond merely commercial transactions and considerations. "An innate tendency is created on part of employees for performing more than the prescribed roles and characters assigned by organizations" (Liaquat \& Mehmood, 2017). Social considerations are given weightage accordingly alongside commercial ones.

The findings from this study re-focuses attention on the fact that businesses are fundamentally a social construct. A business is a social contract created by members of society with the tacit endorsement of the general society. As a social construct, it is imbued with the characteristics of its creators - individuals within society. Commerce is but one of its multifarious concerns. Commerce itself is a social concern as its ultimate beneficiaries are individuals in society. The importance of the social aspect is manifested in important role social capital plays in the typologies.

Concurrent with the re-emphasis of businesses as a social construct is the re-focus on the importance of the local community towards national development. Local communities function best when they are cohesive and empowered, and further research is required as "Community empowerment efforts are central issues that often are often leveled by the government and society, but until now the issue of community empowerment is still in the socialization stage to find a model of development specific community groups, given the complexity of the problems faced by the community itself both individually and in groups" (Nujun \& Pratiwi, 2018).

Public policy needs to be cognizant and take into account these different typologies to ensure social sustainability. The contributions of small businesses towards both commercial and social development needs to be recognized and promoted accordingly. Granted, this research is exploratory in nature and specific public policy with regards to the findings of this research have yet to be developed and tested. Nonetheless, public policy that specifically promotes small businesses and wet markets is recommended as they provide both social and commercial benefits, and 
ultimately promote social sustainability. The re-focus of businesses as fundamentally social constructs have wider public policy implications particularly in town planning and socio-economic policies.

In conclusion, this research has contributed towards the understanding of small businesses in Southeast Asia with findings that have public policy implications. This research also points the way for further studies on small businesses from a sociological perspective particularly with the adoption of the philosophical and methodological framework of phenomenology.

\section{References}

Ahmad, Noor Hazlina \& Seet, Pi-Shen (2010). Gender variations in ethical and socially responsible considerations among SME entrepreneurs in Malaysia. International Journal of Business and Society, 11(1), 77-88

Ali, Muhammad Sibt-e-, Chaudhary, Imran Sharif \& Farooq, Fatima (2018). Impact of Human and Social Capital on Economic Development in Pakistan: Empirical Evidence From Primary Data Analysis. Journal of Accounting and Finance in Emerging Economies, Vol. 1, No. 1, June 2018, 57-64

Barringer, B. R., \& Ireland, R. D. (2012). Entrepreneurship Successfully Launching New Ventures (4th ed.). U.S.A.: Pearson.

Blaikie, Norman (2007). Approaches to Social Enquiry (2nd ed.). UK: Polity Press.

Denscombe, Martyn (2007). The Good Research Guide for small-scale social research projects (3rd ed.). USA: McGraw Hill, Open University Press.

Khan, M. W. J. \& Khalique, M. (2014). An Overview of Small and Medium Enterprises in Malaysia and Pakistan: Past, Present and Future Scenario. Business and Management Horizons. 2(2), 38.

Liaquat, Malta \& Mehmood, Khawaja Khalid (2017). Organization Citizenship Behavior: Notion of Social Exchange Theory. Journal of Business and Social Review in Emerging Economics, Vol. 3, No. 2, December 2017, 209-215

Mahmood, Zeeshan \& Ahmad, Zubir (2015). Quest for Alternative Sociological Perspectives on Corporate Social and Environmental Reporting (2015). Journal of Accounting and Finance in Emerging Economies, Vol. 1, No. 2, December 2015, 135-153

Maykut, Pamela \& Morehouse, Richard (1994). Beginning qualitative research: A philosophy and practical guide. London: The Falmer Press.

Nujum, Syamsu \& Pratiwi, Fadhia Raty (2018). Poverty Alleviation through Institutional Empowerment of Social and Economy on Poor Society in Gowa Regency. Review of Economics and Development Studies, Vol. 4, No. 1, June 2018, 23-29

Ong, Beng Kok (2010). Abductive Research Strategy (ARS) and the Generation of Grounded Concepts: Two Empirical Examples. Paper presented at the The 11th International Interdisplinary Conference: Advances in Qualitative Methods, Coast Plaza Hotel \& Suites Vancouver, British Columbia.

Palinkas, Lawrence A.; Horwitz, Sarah M.; Green, Carla A.; Wisdom, Jennifer P.; Duan, Naihua \& Hoagwood, Kimberly (2013). Purposeful Sampling for Qualitative Data Collection and Analysis in Mixed Method Implementation Research. Administration and Policy Mental Health and Mental Health Services Research 42(5) $\quad$ November 2013. http://www.researchgate.net/publication/258315317_Purposeful_Sampling_for_Qualitative_Data_Collectio n_and_Analysis_in_Mixed_Method_Implementation_Research

Patton, M. Q. (2002). Qualitative research and evaluation methods (3rd ed.). Thousand Oaks, CA: Sage.

Quinn, J. J. (1997). Personal Ethics and Business Ethics: The Ethical Attitudes of Owner/Managers of Small Business. Journal of Business Ethics, 16(2), pp. 119-127.

Robu, M. (2013). The Dynamic and Importance of SMEs in Economy. The USV Annals of Economics and Public Administration, 13(1(17)), 84-89.

Rasheed, Rabia \& Rahman, Maria Abdul (2016). Impact of Social and Religious Beliefs on SMEs Intention towards Adoption of Formal Finance: A Proposed Model. Journal of Business and Social Review in Emerging Economics, Vol 2, No. 2, December 2016, 167-174

Schutz, Alfred (1963). Concept and theory formation in the social sciences. Philosophy of the Social Sciences, 231249.

Smith, Adam (2007). The Wealth of Nations (C. J. Bullock Ed. Originally published in 1901 ed.). New York: Cosim, Inc.

Spence, Laura J. (1999). Does Size Matter? The State of the Art of Small Business Ethics, Business Ethics: A European Review, 8(3), July, 163-174 
Spence, Laura J. \& Rutherford, Robert (2000). Social responsibility, profit maximisation and the small firm ownermanager. Journal of Small Business and Enterprise Development, 8(2), 126-139

The World Bank. (2017). "Small is the New Big" - Malaysian SMEs Help Energize, Drive Economy. Retrieved from http://www.worldbank.org/

Vyakarnam, S. B., Myers, A. \& Burnett, D. (1997). Towards an Understanding of Ethical Behavior in Small Firms. Journal of Business Ethics, 16(15), 1625-1636. 